\title{
Video-assisted thoracic surgery reduces early postoperative stress. A single-institutional prospective randomized study
}

This article was published in the following Dove Press journal:

Therapeutics and Clinical Risk Management

12 January 2016

Number of times this article has been viewed

\author{
Christos Asteriou' \\ Achilleas Lazopoulos' \\ Thomas Rallis' \\ Apostolos S Gogakos' \\ Dimitrios Paliouras' \\ Kosmas Tsakiridis ${ }^{2}$ \\ Athanasios Zissimopoulos ${ }^{3}$ \\ Drosos Tsavlis ${ }^{4}$ \\ Konstantinos Porpodis ${ }^{4}$ \\ Wolfgang Hohenforst- \\ Schmidt ${ }^{5}$ \\ loannis Kioumis ${ }^{4}$ \\ John Organtzis ${ }^{4}$ \\ Konstantinos Zarogoulidis ${ }^{4}$ \\ Paul Zarogoulidis ${ }^{4}$ \\ Nikolaos Barbetakis' \\ 'Department of Thoracic Surgery, \\ Theagenio Cancer Hospital, \\ Thessaloniki, Greece; ${ }^{2}$ Cardiothoracic \\ Surgery Department, Saint Luke \\ Private Hospital, Panorama, \\ Thessaloniki, Greece; ${ }^{3}$ Nuclear \\ Medicine Department, University \\ General Hospital of Alexandroupolis, \\ Democritus University of Thrace, \\ Alexandroupolis, Greece; ${ }^{4}$ Pulmonary \\ Department-Oncology Unit, \\ "G Papanikolaou" General Hospital, \\ Aristotle University of Thessaloniki, \\ Thessaloniki, Greece; ${ }^{5}$ Medical Clinic I, \\ "Fuerth" Hospital, University of \\ Erlangen, Fuerth, Germany
}

Correspondence: Paul Zarogoulidis Pulmonary Department-Oncology Unit, "G Papanikolaou" General Hospital, Aristotle University of Thessaloniki,

Exohi II 0057010 Thessaloniki, Greece

Tel +30 6977271974

Fax +302310992424

Email pzarog@hotmail.com
Background: Video-assisted thoracic surgery (VATS) has been shown to effectively reduce postoperative pain, enhance mobilization of the patients, shorten in-hospital length of stay, and minimize postoperative morbidity rates. The aim of this prospective study is to evaluate neuroendocrine and respiratory parameters as stress markers in cancer patients who underwent lung wedge resections, using both mini muscle-sparing thoracotomy and VATS approach.

Methods: The patients were randomly allocated into two groups: Group A $(n=30)$ involved patients who were operated on using the VATS approach, while in group B $(n=30)$, the mini muscle-sparing thoracotomy approach was used. Neuroendocrine and biological variables assessed included blood glucose levels, C-reactive protein (CRP) levels, cortisol, epinephrine, and adrenocorticotropic hormone $(\mathrm{ACTH})$ levels. Arterial oxygen $\left(\mathrm{PaO}_{2}\right)$ and carbon dioxide $\left(\mathrm{PaCO}_{2}\right)$ partial pressure were also evaluated. All parameters were measured at the following time points: 24 hours preoperatively $\left(\mathrm{T}_{1}\right), 4$ hours $\left(\mathrm{T}_{2}\right), 24$ hours $\left(\mathrm{T}_{3}\right), 48$ hours $\left(\mathrm{T}_{4}\right)$, and 72 hours $\left(\mathrm{T}_{5}\right)$, after the procedure.

Results: $\mathrm{PaO}_{2}$ levels were significantly higher 4 and 24 hours postoperatively in group A vs group $\mathrm{B}$, respectively ( $\mathrm{T}_{2}: 94.3$ vs $77.9 \mathrm{mmHg}, P=0.015, \mathrm{~T}_{3}: 96.4$ vs $88.7 \mathrm{mmHg}, P=0.034$ ). Blood glucose ( $\left.\mathrm{T}_{2}: 148 \mathrm{vs} 163 \mathrm{mg} / \mathrm{dL}, P=0.045, \mathrm{~T}_{3}: 133 \mathrm{vs} 159 \mathrm{mg} / \mathrm{dL}, P=0.009\right)$ and CRP values $\left(\mathrm{T}_{2}: 1.6 \mathrm{vs} 2.5 \mathrm{mg} / \mathrm{dL}, P=0.024, \mathrm{~T}_{3}: 1.5 \mathrm{vs} 2.1 \mathrm{mg} / \mathrm{dL}, P=0.044\right)$ were found increased in both groups 4 and 24 hours after the procedure. However, their levels were significantly lower in the VATS group of patients. ACTH and cortisol values were elevated immediately after the operation and became normal after 48 hours in both groups, without significant difference. Postoperative epinephrine levels measured in group A vs group B, respectively, $\left(\mathrm{T}_{2}: 78.9\right.$ vs $\left.115.6 \mathrm{ng} / \mathrm{L}, P=0.007, \mathrm{~T}_{3}: 83.4 \mathrm{vs} 122.5 \mathrm{ng} / \mathrm{L}, P=0.012, \mathrm{~T}_{4}: 67.4 \mathrm{vs} 102.6 \mathrm{ng} / \mathrm{L}, P=0.021\right)$. The levels were significantly higher in group $\mathrm{B}$.

Conclusion: This study confirmed that minimally invasive thoracic surgery, by means of VATS, significantly reduces the acute-phase response and surgical stress, while enables better postoperative oxygenation.

Keywords: VATS, stress, markers, randomized controlled trial (RCT)

\section{Introduction}

Not many people may argue that in the last decades thoracic surgery has made a very important step toward minimally invasive techniques by utilizing video-assisted thoracic surgery (VATS), with respect to both diagnosis and treatment of early-stage lung cancer, while numerous studies support the prevalence of VATS over the classic open thoracotomy approach. ${ }^{1-5}$ VATS lung resections are safe and equally effective as lung resections achieved using thoracotomy. ${ }^{6,7}$ 
The role of minimally invasive techniques in abdominal surgery and the impact they exert in metabolism, inflammatory, and immunological response has been well-described over the last years in the international literature. ${ }^{8}$ Moreover, certain studies focused on their importance in thoracic surgery. ${ }^{9}$ Increased surgical stress and systemic inflammatory response are associated with higher rates of morbidity and mortality. Furthermore, in cancer patients, open thoracotomy approach induces large immunologic changes, which may increase the rate of complications. ${ }^{10,11}$

The aim of this study was to evaluate in a prospective manner certain neuroendocrine and respiratory parameters, such as postoperative oxygenation and stress markers, in cancer patients who underwent lung wedge resections, using both mini muscle-sparing thoracotomy and VATS approach.

\section{Patients and methods}

From September 2012 to January 2014, 60 patients undergoing elective pulmonary sublobar wedge resections were enrolled in this prospective, single-institutional, randomized study. After study approval by the Theagenio Cancer Hospital Institutional Research Ethics Committee and after written informed consent was obtained from all patients, blinded randomization, using computer-generated random allocations, was performed. The patients were randomly assigned to one of two groups: Group A $(n=30)$ involved patients who were operated on using the VATS approach, while in group $B(n=30)$, the mini muscle-sparing thoracotomy approach was used (Figure 1).

Demographic and preoperative patient data are shown in Table 1. Age <75 years, forced expiratory volume in
1 second $\geq 1 \mathrm{~L}$, and American Society of Anesthesiologists Classification System $\leq 3$ were defined as the inclusion criteria. Exclusion criteria involved emergency surgery and reoperation. The study is registered at ClinicalTrials.gov, number NCT01397045.

\section{Surgical strategy}

In group $\mathrm{B}$, access to the pleural cavity was obtained by a limited $(4-5 \mathrm{~cm})$ posterolateral thoracotomy, preserving latissimus dorsi and partially dividing serratus anterior muscle. In VATS approach group, three stab incisions were made over the lateral thoracic wall (three holes technique). The lowest hole was located at the middle axillary line just above the level of the diaphragm and served as the entrance point for a $0^{\circ}$ fiber-optic camera. The other two incisions were carried out at the posterolateral and the anterolateral thoracic wall, under direct thoracoscopic vision, in such a way as to facilitate the access to the pulmonary lesions. In both groups, a $60 \mathrm{~mm}$ endostapler was used in order to perform pulmonary wedge sublobar resection. Two 32 French chest tubes were placed upon the completion of the operation.

\section{Anesthetic and postoperative management}

All patients received premedication and anesthesia induction using the same method. Tracheal intubation was achieved with the use of a double-lumen tube under bronchoscopic guidance in all cases. Patients' arterial blood pressure, electrocardiogram, central venous pressure, oxygen saturation $\left(\mathrm{SpO}_{2}\right)$, end-tidal carbon dioxide $\left(\mathrm{ETCO}_{2}\right)$, and blood gas values were constantly monitored. Postoperative systemic analgesia was identical for both groups. All patients were

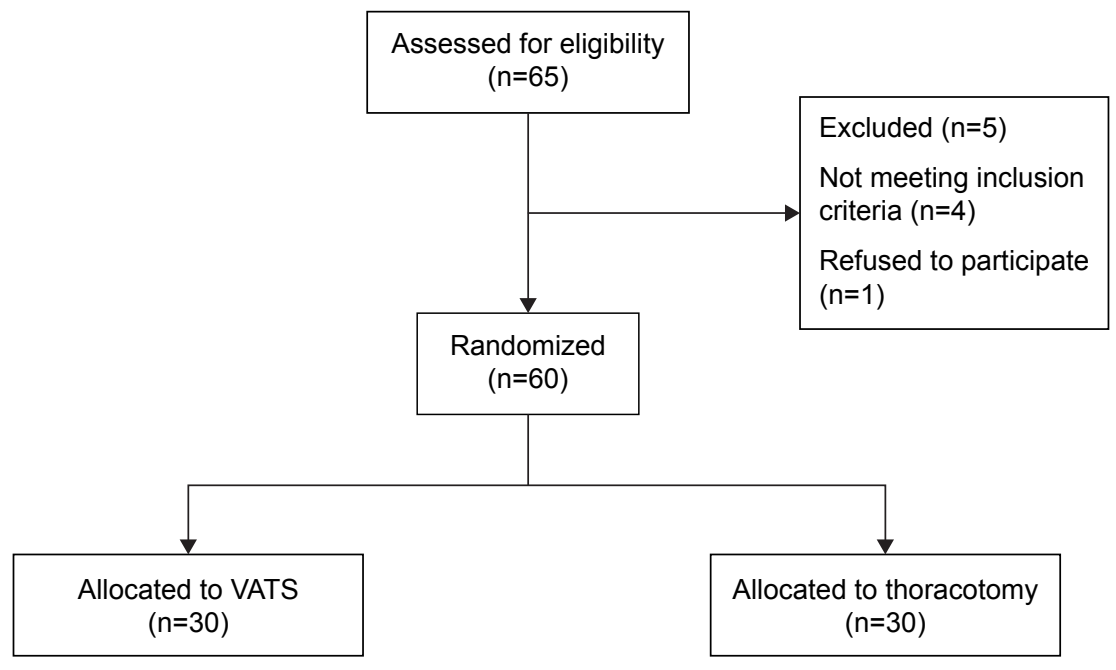

Figure I Flow chart depicting trial phases.

Abbreviation: VATS, video-assisted thoracic surgery. 
Table I Preoperative patients' characteristics per treatment group assigned

\begin{tabular}{|c|c|c|c|}
\hline & VATS $(n=30)$ & Thoracotomy $(n=30)$ & $P$-value \\
\hline Age (years) & $57.7 \pm 18.7$ & $60.8 \pm 14.2$ & 0.132 \\
\hline Sex (male) & $17(56.7)$ & $18(60)$ & 0.463 \\
\hline Height (m) & $1.7 \pm 0.1$ & $1.7 \pm 0.2$ & 0.678 \\
\hline Weight (kg) & $79.6 \pm 14.7$ & $80.2 \pm 16.5$ & 0.583 \\
\hline Body mass index $\left(\mathrm{kg} / \mathrm{m}^{2}\right)$ & $27.3 \pm 4.1$ & $27.4 \pm 5.1$ & 0.734 \\
\hline $\mathrm{FEV}_{1}(\mathrm{~L})$ & $2.3 \pm 0.7$ & $2.4 \pm 0.7$ & 0.415 \\
\hline $\mathrm{FVC}(\mathrm{L})$ & $3.1 \pm 0.9$ & $3.2 \pm 0.8$ & 0.372 \\
\hline $\mathrm{FEV}_{1} / \mathrm{FVC}$ & $0.7 \pm 0.2$ & $0.7 \pm 0.3$ & 0.653 \\
\hline \multicolumn{4}{|l|}{ ASA classification } \\
\hline Class I & $7(23.3)$ & $9(30)$ & 0.732 \\
\hline Class 2 & $17(56.7)$ & $14(46.7)$ & \\
\hline Class 3 & $6(20)$ & $7(23.3)$ & \\
\hline \multicolumn{4}{|l|}{ Neoadjuvant therapy } \\
\hline None & $19(63.3)$ & $17(56.7)$ & 0.379 \\
\hline Chemotherapy & $7(23.3)$ & $8(26.7)$ & \\
\hline Chemotherapy and Radiotherapy & $4(13.4)$ & $5(16.6)$ & \\
\hline Coronary artery disease & $5(16.7)$ & $4(13.3)$ & 0.208 \\
\hline Atrial fibrillation & $3(10)$ & $4(13.3)$ & 0.765 \\
\hline Hypertension & $16(53.3)$ & $18(60)$ & 0.456 \\
\hline Diabetes mellitus & $14(46.7)$ & $12(40)$ & 0.319 \\
\hline
\end{tabular}

Note: Data are mean \pm standard deviation or absolute numbers (percentages).

Abbreviations: VATS, video-assisted thoracic surgery; FEV , forced expiratory volume in I second; FVC, forced vital capacity; ASA, American Society of Anesthesiologists.

mobilized from the first postoperative day, and the thoracic tubes were removed when output was $<200 \mathrm{~mL}$ in 24 hours and no air leakage was present.

\section{Study endpoints}

Neuroendocrine and biological variables assessed included blood glucose levels, C-reactive protein (CRP) levels, cortisol, epinephrine, and adrenocorticotropic hormone (ACTH) levels. Arterial oxygen $\left(\mathrm{PaO}_{2}\right)$ and carbon dioxide $\left(\mathrm{PaCO}_{2}\right)$ partial pressure were also evaluated. All parameters were measured at the following time points: 24 hours preoperatively $\left(\mathrm{T}_{1}\right)$ and 4 hours $\left(\mathrm{T}_{2}\right), 24$ hours $\left(\mathrm{T}_{3}\right), 48$ hours $\left(\mathrm{T}_{4}\right)$, and 72 hours $\left(\mathrm{T}_{5}\right)$, after the procedure. Significant perioperative variables were also recorded and analyzed: number of the segments resected, morphology of the lesion, major cardiopulmonary complications, in-hospital length of stay, and 30-day mortality. The primary endpoint of the study was the effect of VATS on epinephrine levels. Cortisol, ACTH, blood glucose, and CRP levels served as secondary endpoints.

\section{Statistical analysis}

Power analysis was employed to detect appropriate sample size. We have calculated that the average morbidity rate in our institution using mini muscle-sparing thoracotomy approach is about $5 \%$. We supposed that implementation of VATS approach is expected to reduce the corresponding rates up to $30 \%$. Setting the level of type I error $(\alpha)$ at
0.05 and the desired power of the study $(1-\beta)$ at $80 \%$, we calculated that each group should include at least 30 subjects (G*Power v. 3.1.2, Heinrich-Heine University, Düsseldorf, Germany). Statistical analysis was performed using the SPSS 17.0 software (SPSS, Chicago, IL, USA) for windows. Continuous data are presented as mean \pm standard deviation, while categorical variables are presented as absolute numbers and percentages. Normal distribution was assessed by the Kolmogorov-Smirnov test. Univariate comparison of means was made using Student's $t$ - and Mann-Whitney $U$-tests when appropriate. Comparisons between percentages were assessed using the chi-square test. The level of statistical significance was set at 0.05 .

\section{Results}

Perioperative clinical data are shown in Table 2. Duration of operation was shorter in group A; however, this did not reach statistical significance. The number of pulmonary segments resected was similar in both groups, as was as the morphology of the lesions. The pathology of each resected nodule is shown in Table 3. Tumor nodes metastasis staging of lung cancer patients and regimen of neoadjuvant therapy used is shown in Table 4. Furthermore, the location of resections did not significantly differ among the groups. No major cardiopulmonary complications or death were documented in the VATS group, while one patient died from pulmonary embolism on the sixth postoperative day in group B. Mean duration of hospitalization was significantly shorter in group A 
Table 2 Perioperative clinical parameters

\begin{tabular}{|c|c|c|c|}
\hline & VATS $(n=30)$ & Thoracotomy $(n=30)$ & $P$-value \\
\hline Duration of operation (minutes) & $63.5 \pm 3.1$ & $65.1 \pm 3.2$ & 0.057 \\
\hline Segments resected & $2.3 \pm 1.5$ & $2.4 \pm 1.3$ & 0.534 \\
\hline \multicolumn{4}{|l|}{ Location of segments resected } \\
\hline Right upper lobe & $4(13.3)$ & $4(13.3)$ & 0.695 \\
\hline Right middle lobe & $3(10)$ & $6(20)$ & \\
\hline Right lower lobe & $9(30)$ & $5(16.7)$ & \\
\hline Left upper lobe & $6(20)$ & $7(23.3)$ & \\
\hline Left lower lobe & $8(26.7)$ & $8(26.7)$ & \\
\hline \multicolumn{4}{|l|}{ Morphology of the nodule } \\
\hline Non-neoplastic & II (36.7) & $14(46.7)$ & 0.876 \\
\hline Neoplastic primary malignant & $4(13.3)$ & $3(10)$ & \\
\hline Neoplastic secondary malignant & $15(50)$ & $13(43.3)$ & \\
\hline Major cardiopulmonary complications & $0(0)$ & I (3.3) & 0.986 \\
\hline In-hospital stay (days) & $5.1 \pm 1.4$ & $6.7 \pm 1.3$ & 0.011 \\
\hline 30-day mortality & $0(0)$ & I (3.3) & 0.986 \\
\hline
\end{tabular}

Notes: Data are mean \pm standard deviation or absolute numbers (percentages). Bold indicates a statistically significant value.

Abbreviation: VATS, video assisted thoracic surgery.

Table 3 Pathology of resected nodules

\begin{tabular}{|c|c|c|c|}
\hline & VATS $(n=30)$ & Thoracotomy $(n=30)$ & $P$-value \\
\hline Non-neoplastic & II (36.7) & $14(46.7)$ & 0.546 \\
\hline Pulmonary hamartoma & $4(13.3)$ & $5(16.7)$ & 0.312 \\
\hline Pulmonary granuloma & $3(10)$ & $4(13.3)$ & 0.398 \\
\hline Chronic pulmonary inflammation & $2(6.7)$ & $3(10)$ & 0.257 \\
\hline Pulmonary fibrosis with fibroblastic plugs & $2(6.7)$ & $2(6.7)$ & 0.818 \\
\hline Neoplastic primary malignant & $4(13.3)$ & $3(10)$ & 0.398 \\
\hline NSCLC - squamus cell carcinoma & $0(0)$ & I (3.3) & 0.432 \\
\hline NSCLC - adenocarcinoma & $\mathrm{I}(3.3)$ & $\mathrm{I}(3.3)$ & 0.756 \\
\hline NSCLC - large cell carcinoma & I (3.3) & $0(0)$ & 0.432 \\
\hline Small-cell lung carcinoma & $2(6.7)$ & $\mathrm{I}(3.3)$ & 0.345 \\
\hline Neoplastic secondary malignant & $15(50)$ & $13(43.3)$ & 0.414 \\
\hline Breast carcinoma & $5(16.7)$ & $4(\mid 3.3)$ & 0.312 \\
\hline Adenocarcinoma of the colon & $2(6.7)$ & $4(13.3)$ & 0.262 \\
\hline Carcinoma of the larynx & $2(6.7)$ & $3(10)$ & 0.257 \\
\hline Papillary carcinoma of the thyroid gland & I (3.3) & $\mathrm{I}(3.3)$ & 0.756 \\
\hline Malignant melanoma & $2(6.7)$ & $0(0)$ & 0.388 \\
\hline Bile duct carcinoma & $\mathrm{I}(3.3)$ & $0(0)$ & 0.432 \\
\hline Femoral leiomyosarcoma & $0(0)$ & I (3.3) & 0.432 \\
\hline Ovarian carcinoma & I (3.3) & $0(0)$ & 0.432 \\
\hline Neuroendocrine carcinoma of low differentiation & I (3.3) & $0(0)$ & 0.432 \\
\hline
\end{tabular}

Notes: Data are absolute numbers (percentages).

Abbreviations: VATS, video assisted thoracic surgery; NSCLC, non-small-cell lung carcinoma.

Table 4 TNM staging of lung cancer patients and regimen of neoadjuvant therapy used

\begin{tabular}{lll}
\hline Pathology & TNM stage & Neoadjuvant therapy \\
\hline Squamous cell carcinoma & T2aNOMO - IB & None \\
Adenocarcinoma & TIbNOMO - IA & None \\
Adenocarcinoma & T2aNOMO - IB & None \\
Large cell carcinoma & T2aNOMO - IB & None \\
Small-cell lung carcinoma & T2bN2MIb - IV & Carboplatin and etoposide \\
& & Radiotherapy \\
Small-cell lung carcinoma & T2bNIM0 - IIB & Gemcitabine and carboplatin \\
Small-cell lung carcinoma & T2bN2M0 - IIIA & Gemcitabine and carboplatin \\
\hline
\end{tabular}

Abbreviation: TNM, tumor nodes metastasis. 


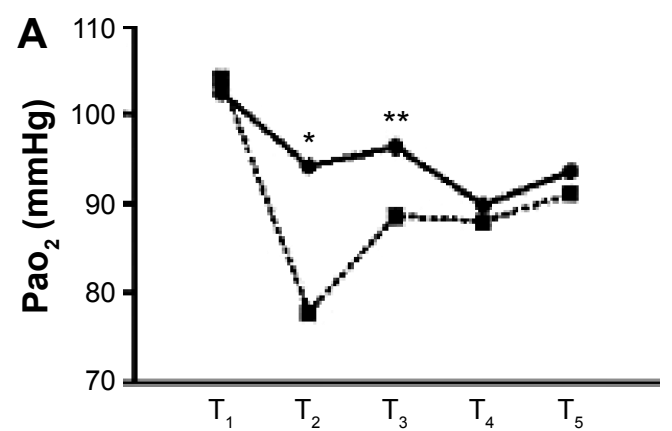

Time points

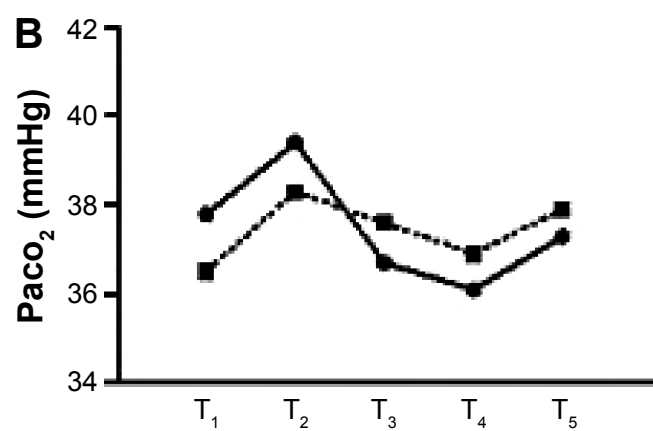

Time points

VATS - Thoracotomy

Figure 2 Blood gas levels.

Notes: $(\mathbf{A})$ Arterial oxygen $\left(\mathrm{PaO}_{2}\right)(* \mathrm{P}=0.015, * * \mathrm{P}=0.034)$ and $(\mathbf{B})$ carbon dioxide $\left(\mathrm{PaCO}_{2}\right)$ partial pressure data between groups at the measured time points: 24 hours preoperatively $\left(T_{1}\right)$ and 4 hours $\left(T_{2}\right), 24$ hours $\left(T_{3}\right), 48$ hours $\left(T_{4}\right)$, and 72 hours $\left(T_{5}\right)$, after the procedure.

Abbreviation: VATS, video-assisted thoracic surgery.

(5.1 vs 6.7 days, $P=0.011$ ). No conversion from VATS to open thoracotomy was necessary.

Preoperative values of neuroendocrine, biological, and respiratory variables were similar in both groups. Regarding respiratory parameters, $\mathrm{PaO}_{2}$ levels were significantly higher 4 and 24 hours postoperatively in group $\mathrm{A}\left(\mathrm{T}_{2}: 94.3\right.$ vs $77.9 \mathrm{mmHg}, P=0.015, \mathrm{~T}_{3}$ : 96.4 vs $88.7 \mathrm{mmHg}, P=0.034$ ), while $\mathrm{Paco}_{2}$ levels did not differ between the groups (Figure 2). Blood glucose ( $\mathrm{T}_{2}: 148 \mathrm{vs} 163 \mathrm{mg} / \mathrm{dL}, P=0.045$, $\left.\mathrm{T}_{3}: 133 \mathrm{vs} 159 \mathrm{mg} / \mathrm{dL}, P=0.009\right)$ and $\mathrm{CRP}$ values $\left(\mathrm{T}_{2}: 1.6\right.$ vs $2.5 \mathrm{mg} / \mathrm{dL}, P=0.024, \mathrm{~T}_{3}: 1.5 \mathrm{vs} 2.1 \mathrm{mg} / \mathrm{dL}, P=0.044$ ) were found to be increased in both groups 4 and 24 hours after the procedure. However, their levels were significantly lower in the VATS group of patients (Figure 3). ACTH and cortisol values were elevated immediately after the operation and became normal after 48 hours in both groups, without significant difference (Figure 4). Postoperative epinephrine levels measured ( $\mathrm{T}_{2}: 78.9 \mathrm{vs} 115.6 \mathrm{ng} / \mathrm{L}, P=0.007, \mathrm{~T}_{3}: 83.4$ vs $122.5 \mathrm{ng} / \mathrm{L}, P=0.012, \mathrm{~T}_{4}: 67.4$ vs $102.6 \mathrm{ng} / \mathrm{L}, P=0.021$ ) were significantly higher in group B (Figure 4).

\section{Discussion}

The role of VATS in the treatment of patients with pulmonary nodules has been upgraded during the last years, and the majority of thoracic surgeons consider it as the most suitable approach. The advantages of VATS over thoracotomy have been well-established by numerous studies. Less postoperative pain, better mobilization of the arm and shoulder, shorter duration of hospitalization, and less morbidity in contrast to thoracotomy characterize VATS procedures. ${ }^{12-14}$

All patients who received neoadjuvant therapy, as shown in Table 1, were initially operated on for malignancy located in organs other than the lungs (eg, breast, colon, etc). Therefore, these first operations were followed by

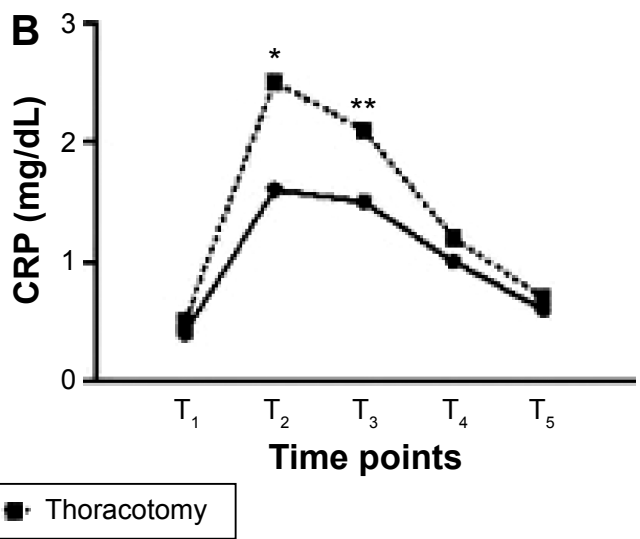

Figure 3 Glucose and c-reactive protein levels.

Notes: $(\mathbf{A})$ Levels of blood glucose $(* P=0.045, * * P=0.009)$ and $(\mathbf{B})$ CRP $(* P=0.024, * * P=0.044)$ between groups at the measured time-points: 24 hours preoperatively $\left(T_{1}\right), 4$ hours $\left(T_{2}\right), 24$ hours $\left(T_{3}\right), 48$ hours $\left(T_{4}\right)$, and 72 hours $\left(T_{5}\right)$, after the procedure. Abbreviations: VATS, video-assisted thoracic surgery; CRP, C-reactive protein. 
A

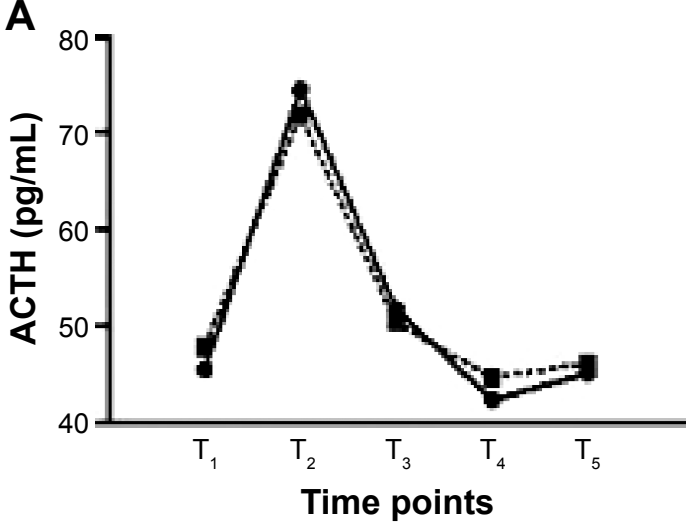

B

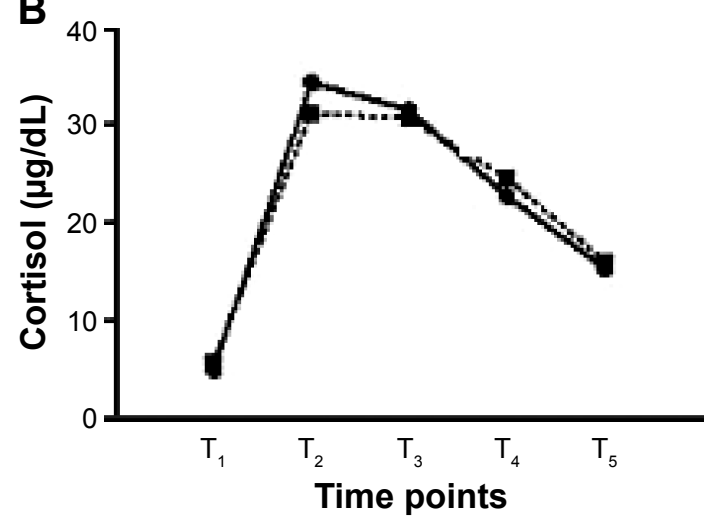

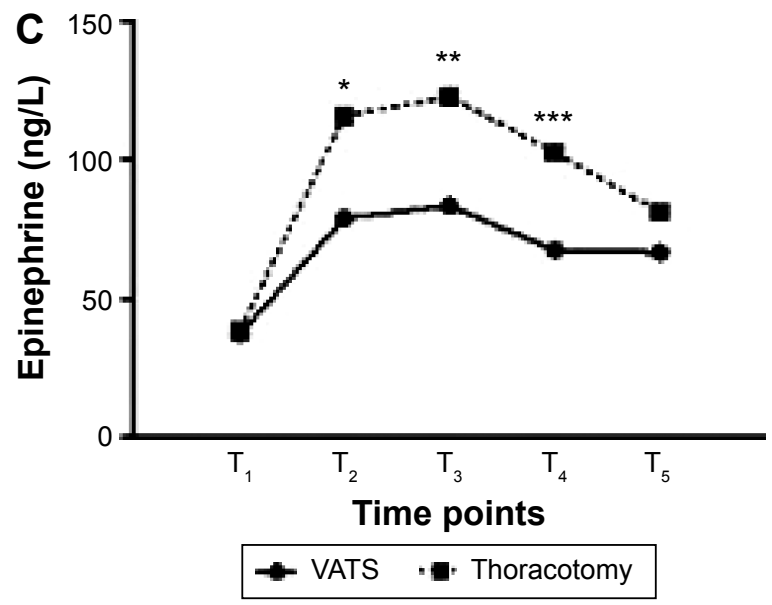

Figure 4 Hormone levels.

Notes: $(\mathbf{A})$ Levels of $A C T H,(B)$ cortisol, and $(\mathbf{C})$ epinephrine $\left(* P=0.007,{ }^{* *} P=0.012,{ }^{* * *} P=0.021\right)$ between groups at the measured time-points: 24 hours preoperatively $\left(T_{1}\right)$, 4 hours $\left(T_{2}\right), 24$ hours $\left(T_{3}\right), 48$ hours $\left(T_{4}\right)$, and 72 hours $\left(T_{5}\right)$, after the procedure.

Abbreviations: VATS, video-assisted thoracic surgery; ACTH, adrenocorticotropic hormone.

neoadjuvant therapy when appropriate. Neoadjuvant therapy was performed before the pulmonary resection. The minimum time interval between the last therapy and the pulmonary resection was at least 1 month. It is unlikely that stress variables' levels could be affected after this time interval. Moreover, baseline measurements were not statistically significant, and both groups included similar proportion of patients who had received neoadjuvant therapy.

This study confirmed that VATS is associated with significantly higher postoperative $\mathrm{PaO}_{2}$ values. Elevated $\mathrm{PaO}_{2}$ levels imply optimum oxygenation, possibly attributed to the reduced postoperative pain experienced in patients operated using the thoracoscopic approach. Lower $\mathrm{PaO}_{2}$ levels in the open-approach group correlate with ineffective postoperative respiratory function due to increased thoracotomy related pain. ${ }^{15} \mathrm{PaCO}_{2}$ levels recorded were similar in both groups. $\mathrm{CO}_{2}$ exchange in alveoli is independent from the approach used and does not relate to postoperative thoracotomy pain. ${ }^{16}$

The stress response to surgery, with the production of mediators, cytokines, acute-phase proteins, adrenocorticoids, and catecholamines is influenced by the degree of surgical trauma, general anesthesia, and analgesics. Both general anesthesia and postoperative analgesic treatment were identical for all patients included in this study.

Lower insulin levels after induction of anesthesia and during surgery, along with decreased peripheral use of insulin due to perioperative increased "insulin resistance" effect, resulted in elevated concentration of blood glucose in surgical patients. Connection between elevated glucose levels after surgery and intensity of surgical injury has already been described. ${ }^{17} \mathrm{In}$ correlation with these findings, patients allocated to group B were characterized by significantly elevated blood glucose levels, which returned to normal on the third postoperative day. On the contrary, VATS group of patients experienced a milder postoperative hyperglycemia.

CRP is an acute-phase response marker produced in the liver. Along with interleukin-6, fibrinogen, and other proteins, CRP acts as an inflammatory mediator. Minimally invasive thoracic surgery, utilizing VATS, is associated with minor increase in serum levels of these mediators, ${ }^{18}$ due to limited trauma. Reduced inflammatory response in group A was confirmed in this study. 
Increase of ACTH during the operation results from stimulation of the anterior pituitary by hypothalamic releasing factors. ${ }^{19}$ Surgery has been recognized as one of the most potent activators of ACTH secretion. ${ }^{17} \mathrm{ACTH}$ in turn stimulates the adrenal cortical secretion of glucocorticoids, thus contributing to elevated serum levels of cortisol. ACTH and cortisol levels are strongly related. No significant difference between two groups of this trial was recorded regarding postoperative measurements of these stress markers. As a result, the degree of surgical trauma itself does not significantly influence the stress response as far as ACTH and cortisol values are concerned. Identical changes in postoperative levels of these hormones in both groups are probably attributed to general anesthesia in combination with the extent of pulmonary resection.

Catecholamine levels increase as a result of the hypothalamic activation of the sympathetic autonomous nervous system and the stimulation of the adrenal medulla. Epinephrine is a strong stress indicator. ${ }^{17}$ Postoperative epinephrine levels recorded in this study were significantly higher in group B in comparison with group A. In addition, even 72 hours after the procedure, these levels remained elevated. This finding is consistent with a strong correlation between the epinephrine concentration increase and the extent of the surgical trauma, which is also verified by several studies. ${ }^{18}$

In conclusion, this study confirmed that minimally invasive thoracic surgery, by means of VATS, significantly reduces the acute-phase response and surgical stress, while enabling better postoperative oxygenation. Larger randomized trials are expected to illuminate the impact of these important findings on the treatment of cancer patients and establish VATS as the approach of choice.

\section{Disclosure}

The authors report no conflicts of interest in this work.

\section{References}

1. Craig SR, Leaver HA, Yap PL, et al. Acute phase responses following minimal access and conventional thoracic surgery. Eur J Cardiothorac Surg. 2001;20:455-463.
2. Whitson BA, D'Cunha J, Andrade RS, et al. Thoracoscopic versus thoracotomy approaches to lobectomy: differential impairment of cellular immunity. Ann Thorac Surg. 2008;86:1735-1744.

3. Koizumi K, Haraguchi S, Hirata T, et al. Video-assisted lobectomy in elderly lung cancer patients. Jpn J Thorac Cardiovasc Surg. 2002;50:15-22.

4. Muraoka M, Oka T, Akamine S, et al. Video-assisted thoracic surgery lobectomy reduces the morbidity after surgery for stage I non-small cell lung cancer. Jpn J Thorac Cardiovasc Surg. 2006;54:49-55.

5. Whitson BA, Andrade RS, Boettcher A, et al. Video-assisted thoracoscopic surgery is more favorable than thoracotomy for resection of clinical stage I non-small cell lung cancer. Ann Thorac Surg. 2007;83: 1965-1970.

6. Kirby TJ, Rice TW. Thoracoscopic lobectomy. Ann Thorac Surg. 1993; 56:784-786.

7. Sugi K, Kaneda Y, Esato K. Video-assisted thoracoscopic lobectomy achieves a satisfactory long-term prognosis in patients with clinical stage IA lung cancer. World J Surg. 2000;24:27-30.

8. Puggioni A, Wong LL. A metaanalysis of laparoscopic cholecystectomy in patients with cirrhosis. J Am Coll Surg. 2003;197:921-926.

9. Walker WS, Leaver HA, Yap PL. The immune response to surgery: conventional and video assisted thorascopic pulmonary lobectomy. In: Yim APC, editor. Minimal Access Cardiothoracic Surgery. Philadelphia, PA: Saunders; 1999:127-134.

10. Sietses C, Havenith CE, Eijsbouts QA, et al. Laparoscopic surgery preserves monocyte-mediated tumor cell killing in contrast to the conventional approach. Surg Endosc. 2000;14:456-460.

11. Sietses C, Beelen RH, Meijer S, et al. Immunological consequences of laparoscopic surgery, speculations on the cause and clinical implications. Langenbecks Arch Surg. 1999;384:250-258.

12. Walker WS. Major pulmonary resection. In: Walker WS, editor. Video-assisted Thoracic Surgery. Oxford, UK: Isis Medical Media; 1999: 135-159.

13. Yan TD, Black D, Bannon PG, et al. Systematic review and metaanalysis of randomized and nonrandomized trials on safety and efficacy of video-assisted thoracic surgery lobectomy for early-stage non-smallcell lung cancer. J Clin Oncol. 2009;27:2553-2562.

14. Yim AP, Wan S, Lee TW, et al. VATS lobectomy reduces cytokine responses compared with conventional surgery. Ann Thorac Surg. 2000;70:243-247.

15. Catley DM, Thornton C, Jordan C, et al. Pronounced, episodic oxygen desaturation in the postoperative period: its association with ventilatory pattern and analgesic regimen. Anesthesiology. 1985;63:20-28.

16. Tschernko EM, Hofer S, Bieglmayer C, et al. Early postoperative stress: video-assisted resection/lobectomy vs conventional axillary thoracotomy. Chest. 1996;109:1636-1642.

17. Desborough JP. The stress response to trauma and surgery. Br J Anaesth. 2000;85:109-117.

18. Walker WS, Leaver HA. Immunologic and stress responses following video-assisted thoracic surgery and open pulmonary lobectomy in early stage lung cancer. Thorac Surg Clin. 2007;17:241-249.

19. Lyons FM, Meeran K. The physiology of the endocrine system. Int Anesthesiol Clin. 1997;35:1-21.
Therapeutics and Clinical Risk Management

\section{Publish your work in this journal}

Therapeutics and Clinical Risk Management is an international, peerreviewed journal of clinical therapeutics and risk management, focusing on concise rapid reporting of clinical studies in all therapeutic areas, outcomes, safety, and programs for the effective, safe, and sustained use of medicines. This journal is indexed on PubMed Central, CAS,

\section{Dovepress}

EMBase, Scopus and the Elsevier Bibliographic databases. The manuscript management system is completely online and includes a very quick and fair peer-review system, which is all easy to use. Visit $\mathrm{http}: / / \mathrm{www}$.dovepress.com/testimonials.php to read real quotes from published authors. 